\title{
Delayed Neurological Recovery After Ultrasound-Guided Brachial Plexus Block: A Case Report
}

This article was published in the following Dove Press journal: Local and Regional Anesthesia

\author{
Ninadini Shrestha' \\ Bipin Karki (iD) ${ }^{2}$ \\ Megha Koirala' \\ Santosh Acharya $\mathbb{1 D}^{3}$ \\ Pramesh Sunder Shrestha' \\ Subhash Prasad Acharya' \\ 'Department of Anaesthesia, Maharajgunj \\ Medical Campus, Institute of Medicine, \\ Maharajgunj, Kathmandu, Nepal; \\ ${ }^{2}$ Department of Critical Care Medicine, \\ Om Hospital and Research Center Pvt. \\ Ltd, Chabahil, Kathmandu, Nepal; \\ ${ }^{3}$ Department of Critical Care Medicine, \\ Hospital for Advanced Medicine and \\ Surgery, Dhumbarahi, Kathmandu, Nepal
}

Introduction: Brachial plexus blocks are frequently practiced and safe mode of anaesthsia. Although minor complications may occur, major complications are a rarity. However, we report a rare case of prolonged supraclavicular brachial plexus block which required almost 4 months to recover without a perceivable cause.

Case Presentation: A 22-year-old gentleman posted for open reduction and internal fixation of both forearm bones was administered an ultrasound-guided supraclavicular brachial plexus block. The intra-operative period was uneventful. However, the block persisted for a very prolonged period of time. All perceivable causes were ruled out. A total of 19 weeks was required for the entire block to regress with no residual neurological deficits thereafter.

Conclusion: Although peripheral neuropathies are known complications of peripheral nerve blocks, such a prolonged brachial plexus block is a rare event. The only plausible cause for the patient's condition could have been the prolonged drug effect; however, it has been rarely documented.

Keywords: complication, nerve conduction test, neurology, neuropathy

\section{Introduction}

Peripheral nerve blocks for upper limb surgeries are commonly used anaesthetic techniques. They are considered very safe with occasional incidence of peripheral neuropathies of varying duration. ${ }^{1}$ The use of ultrasound in the present time has further decreased such adversities. ${ }^{2,3}$ A complete brachial plexus block for a very prolonged duration is an extremely rare event. We report a case of ultrasoundguided supraclavicular brachial plexus block which persisted for almost 4 months with complete recovery thereafter.

\section{Case Presentation}

A 22-year-old gentleman with American Society of Anesthetists Physical status I (ASA PS I), with history of fall on an outstretched left hand leading to both-bone fracture of left forearm was posted for open reduction and internal fixation with plates and screws at Tribhuvan University Teaching Hospital, Maharajgunj, Kathmandu. Left brachial plexus block was planned and done under ultrasound guidance via the supraclavicular approach with a 25 gauze Quinkes needle. The patient was placed in a semi-recumbent position. Using the linear high-frequency
Correspondence: Bipin Karki

Department of Critical Care Medicine, Om Hospital and Research Center Pvt. Ltd., GPO 13494, Chabahil, Kathmandu, Nepal

Tel +9779841701269

Fax +977 I4466I28

Email karki_bipin@yahoo.com 
ultrasound probe, the needle was introduced from the lateral aspect of the neck just lateral to the sternocleidomastoid muscle after visualization of the brachial plexus. A total of $25 \mathrm{~mL}$ of solution, consisting of $8 \mathrm{~mL}$ of $0.5 \%$ bupivacaine, $2 \mathrm{~mL}(8 \mathrm{mg})$ of dexamethasone, $5 \mathrm{~mL}$ of $2 \%$ lignocaine with adrenaline and $10 \mathrm{~mL}$ of normal saline, was used for injection. Two different points within the brachial plexus connective tissue sheath, one inferior and another supero-lateral to the plexus, were used for injection to ensure the complete block of the plexus. ${ }^{4}$ A complete sensory and motor block of the dermatomal levels cervical fifth to thoracic first (C5 to T1) was attained within $5 \mathrm{~min}$. A mid-arm tourniquet was used by the surgeons with an inflation pressure of $250 \mathrm{~mm}$ of $\mathrm{Hg}$. The tourniquet inflation time was an uninterrupted 118 min and the total duration of surgery was $130 \mathrm{~min}$.

In the postoperative period, during patient assessment, we found out that there was no recovery of the sensory and motor block even after $24 \mathrm{hrs}$. An upper limb ultrasonography (USG) to rule out hematoma was done which showed no abnormalities. After a period of $72 \mathrm{hrs}$ with no recovery, a magnetic resonance imaging (MRI) was done which was also unremarkable. A nerve conduction study was done on day four. The results were normal for all the upper limb nerves. No conduction block was present in any of the peripheral nerves. Neurology consultation was obtained and empirical steroid therapy was started. The patient was discharged on day five without any neurological recovery with a weekly follow up schedule and on physiotherapy. No recovery whatsoever was present until week two. By week three, there was paresthesia with no motor recovery. By week six, there was complete sensory recovery, with motor power of $2 / 5$ in the triceps and biceps. At 11 weeks, there was complete sensory recovery and return of motor power of $4 / 5$ in the biceps and triceps but $0 / 5$ in the interphalangeal joints. At 15 weeks, complete sensory recovery and complete recovery of biceps motor power and triceps with hand muscles power of $3 / 5$. At 19 weeks, there was a complete sensory and motor recovery of the entire limb.

\section{Discussion}

Peripheral nerve blocks are safe procedures with low complication rates, the most common being nerve injuries. The most common mechanisms reported for such injuries are direct trauma by the puncture needle, effect of drugs and adjuvant used and external compressions from haematoma (surgical or anaesthetic source). ${ }^{1,5}$ Peripheral nerve injuries occurring from direct needle injuries have been extensively studied in terms of the type of needle and the direction of penetration. ${ }^{6}$ In our case, a Quincke's type spinal needle of $25 \mathrm{G}$ size was used to inject the drug below the connective tissue sheath of the plexus at two points, one supero-lateral and the other below the brachial plexus. Though the needle trauma could explain the injury to individual nerves, the blockade of the entire brachial plexus is not plausible. The nerve conduction test was also found to be normal which effectively ruled out nerve trauma, though normal results can be obtained sometimes even in nerve injuries especially if done early.

The local anaesthetics have all been shown to have neurotoxicity, but the dosage and concentration of the drugs used $(40 \mathrm{mg}$ at $0.16 \%$ of bupivacaine, $100 \mathrm{mg}$ at $0.4 \%$ of lignocaine with adrenaline) is well below maximum recommended levels. In addition, the combination of two local anaesthetics (lignocaine and bupivacaine) has been found to have no added safety concerns. ${ }^{7,8}$

Use of adjuvants has been shown to increase the duration and quality of block. The duration of blockade, extending well into the postoperative period has been frequently reported, leading to frequent addition of dexamethasone for the same purpose. ${ }^{9}$ However, the degree of prolongation of the duration of blockade seen in our case cannot be attributed to dexamethasone. Also, no reports of neurotoxicity but rather evidence of protection from the neurotoxicity of bupivacaine has been seen. ${ }^{10}$

Addition of adrenaline has been shown to decrease the neural blood supply due to its vasoconstrictor effects. ${ }^{11}$ But such severe hypoperfusion for such a prolonged period of time should have had permanent effects and thus irreversible.

Nerve injuries have also been attributed to the use of tourniquets. The tourniquet pressure to be used has been recommended according to the limb occlusion pressure though the empirical pressure of $250 \mathrm{~mm}$ of $\mathrm{Hg}$ for upper limbs is used extensively. ${ }^{12}$ The duration was also just below 2 hrs. Also this, if were the cause should have lead to the neurological deficit distal to the tourniquet. But this gentleman had deficit throughout the distribution of the brachial plexus including proximal to the tourniquet. Other possible post-surgical causes were ruled out with USG and MRI.

The patient had full neurology recovery of the upper limb by week 19, but the exact cause for such delayed neurological block could never be identified. The only plausible answer could be the effect of drugs themselves, 
namely the combination of neurotoxic local anaesthetics with the vasoconstricting adrenaline.

\section{Conclusion}

Though individual nerve injuries requiring a long time to recover and some even permanent have been reported, the authors are unaware of any report of the entire brachial plexus blockade for such prolonged durations. Only speculations can be made about the cause of this. Cumulative toxicity from two different local anaesthetics along with adrenaline may have been one factor though evidence of interaction of such a degree is lacking at present.

\section{Abbreviations}

ASA PS I, American Society of Anesthetists Physical Status grade I; USG, Ultrasonography; MRI, Magnetic Resonance Imaging; NYSORA, New York Society Of Regional Anesthesia; C5, Cervical Fifth; T1, Thoracic First.

\section{Consent}

Written informed consent for the publication was obtained from the patient himself.

\section{Acknowledgments}

We would like to acknowledge the efforts of Dr. Rajiv Ojha, neurologist and Dr. Shirish Adhikari, orthopedician, who had been actively involved in the patient care and follow up. They showed a lot of patience until the recovery.

\section{Disclosure}

The authors report no conflicts of interest in this work.

\section{References}

1. Brull R, McCartney CJL, Chan VWS, El-Beheiry H. Neurological complications after regional anesthesia: contemporary estimates of risk. Anesth Analg. 2007;104(4):965-974. doi:10.1213/01.ane.0000 258740.17193.ec

2. Gnanaprakasam PV, Selvaraj V. Ultrasound Assessment of Subglottic Region for Estimation of Appropriate Endotracheal Tube Size in Pediatric Anesthesia. J Anaesthesiol Clin Pharmacol. 2017:33(2) 231-235.

3. Davis JJ, Swenson JD, Greis PE, Burks RT, Tashjian RZ. Interscalene block for postoperative analgesia using only ultrasound guidance: the outcome in 200 patients. J Clin Anesth. 2009;21(4):272-277. doi:10.1016/j.jclinane.2008.08.022

4. NYSORA. Ultra-sound guided supraclavicular brachial plexus block. Available from: https://www.nysora.com. Accessed Dec 20, 2019.

5. Lenters TR, Davies J, Matsen FA. The types and severity of complications associated with interscalene brachial plexus block anesthesia: local and national evidence. J Shoulder Elb Surg. 2007;16(4):379387. doi:10.1016/j.jse.2006.10.007

6. Sala-Blanch X, Ribalta T, Rivas E, et al. Structural injury to the human sciatic nerve after intraneural needle insertion. Reg Anesth Pain Med. 2009;34(3):201-205. doi:10.1097/AAP.0b013e31819a2 795

7. Takeda A, Ferraro LHC, Rezende AH, Sadatsune EJ, Falcão Dos LFR, Tardelli MA. Minimum effective concentration of bupivacaine for axillary brachial plexus block guided by ultrasound. Brazilian $J$ Anesthesiol. 2015;65(3):163-169. doi:10.1016/j.bjane.2013.11.007

8. Raizada N, Chandralekha JP, Kumar A. Does compounding and increase in concentration of local anaesthetic agents increase the success rate of brachial plexus block? Indian J Anaesth. 2002;46 (3):193-196.

9. Knight JB, Schott NJ, Kentor ML, Williams BA. Neurotoxicity questions regarding common peripheral nerve block adjuvants in combination with local anesthetics. Curr Opin Anaesthesiol. 2015;28(5):598-604. doi:10.1097/ACO.0000000000000222

10. Choi S, Rodseth R, McCartney CJL. Effects of dexamethasone as a local anaesthetic adjuvant for brachial plexus block: a systematic review and meta-analysis of randomized trials. $\mathrm{Br} J$ Anaesth. 2014;112(3):427-439. doi:10.1093/bja/aet417

11. Prtridge B. The effects of local anesthetics and epinephrine on rat sciatic nerve blood flow. Anesthesiology. 1991;75:243-251. doi:10.1097/00000542-199108000-00012

12. Recommended practices for the use of the pneumatic tourniquet in the perioperative setting. AORN J. 2007;86:640-655. doi:10.1016/j. aorn.2007.09.004

\section{Publish your work in this journal}

Local and Regional Anesthesia is an international, peer-reviewed, open access journal publishing on the development, pharmacology, delivery and targeting and clinical use of local and regional anesthetics and analgesics. The journal welcomes submitted papers covering original research, basic science, clinical studies, reviews \& evaluations, guidelines, expert opinion and commentary, case reports and extended reports. The manuscript management system is completely online and includes a very quick and fair peer-review system, which is all easy to use. Visit http://www.dovepress.com/testimonials. php to read real quotes from published authors. 